Abstract

\title{
Organic Electronic Devices as Multi-Modal Transducers of Cellular Activity ${ }^{\dagger}$
}

\author{
Róisín M. Owens \\ Department of Chemical Engineering and Biotechnology, University of Cambridge, \\ Cambridge CB3 0AS, UK; rmo37@cam.ac.uk; Tel.: +44-1223-763969 \\ † Presented at the Eurosensors 2018 Conference, Graz, Austria, 9-12 September 2018. \\ Published: 14 December 2018
}

In vitro models of biological systems are essential for our understanding of biological systems. In many cases where animal models have failed to translate to useful data for human diseases, physiologically relevant in vitro models can bridge the gap. Many difficulties exist in interfacing complex, 3D models with sensing technology adapted for monitoring function of cells within these models. Polymeric electroactive materials and devices can bridge the gap between hard inflexible materials used for physical transducers and soft, compliant biological tissues. [1] An additional advantage of these electronic materials is their flexibility for processing and fabrication in a wide range of formats. [2] In this presentation, I will discuss our recent progress in adapting conducting polymer devices, including simple electrodes and transistors, to integrate with 3D cell models. [3] We go further, by generating 3D electroactive scaffolds capable of hosting and monitoring cells. [4]

In some cases it is useful to zoom in on interactions occurring at the molecular level, to read out events happening at the level of the cell membrane. In addition to monitoring properties of cells and tissues, electrical monitoring is a powerful tool to monitor transmembrane protein function. [5] I will highlight recent research using biomimetic models of cell membranes interfaced with organic electronic devices for drug discovery.

\section{References}

1. Rivnay, J.; Owens, R.M.; Malliaras, G.G. The Rise of Organic Bioelectronics. Chem. Mater. 2014, 26, $679-685$.

2. Rivnay, J.; Inal, S.; Salleo, A.; Owens, R.M.; Berggren, M.; Malliaras, G.G. Organic electrochemical transistors. Nat. Rev. Mater. 2018, 3, 17086.

3. Pas, J.; Pitsalidis, C.; Koutsouras, D.A.; Quilichini, P.P.; Santoro, F.; Cui, B.; Gallais, L.; O'Connor, R.P.; Malliaras, G.G.; Owens, R.M. Neurospheres on Patterned PEDOT: PSS Microelectrode Arrays Enhance Electrophysiology Recordings. Adv. Biosyst. 2018, 2, 1700164.

4. Inal, S.; Hama, A.; Ferro, M.; Pitsalidis, C.; Oziat, J.; Iandolo, D.; Pappa, A.M.; Hadida, M.; Huerta, M.; Marchat, D.; et al. Conducting Polymer Scaffolds for Hosting and Monitoring 3D Cell Culture. Adv. Biosyst. 2017, 1, 1700052.

5. Zhang, Y.; Inal, S.; Hsia, C.Y.; Ferro, M.; Ferro, M.; Daniel, S.; Owens, R.M. Supported Lipid Bilayer Assembly on PEDOT: PSS Films and Transistors. Adv. Funct. Mater. 2016, 26, 7304-7313.

(C) 2018 by the authors. Licensee MDPI, Basel, Switzerland. This article is an open access article distributed under the terms and conditions of the Creative Commons Attribution (CC BY) license (http://creativecommons.org/licenses/by/4.0/). 